\title{
Acupuncture Analgesia and its Future
}

Preface : Since 1958 when acupuncture analgesia was transmitted to many countries from the People's Republic of China by the reporters of the United States who accompanied President Nixon, acupuncture and Oriental medicine have been highly praised by journalism throughout the world, but they must now be re-evaluated by the medical doctors who are concerned about not only the good points but also the bad points of acupuncture. I would like to consider with you for a little while, the various aspects and meanings of acupuncture and to criticize $t_{h e}$ merits and indications of acupuncture and acupuncture analgesia.

Nearly two thousand years have passed since acupuncture was introduced to Japan firstly from Zui (old China) py Chiso. Acupuncture and herbal medicine were the main treatment methods until in the Meiji era (1868) when Western medicine was imported

Fig. 1

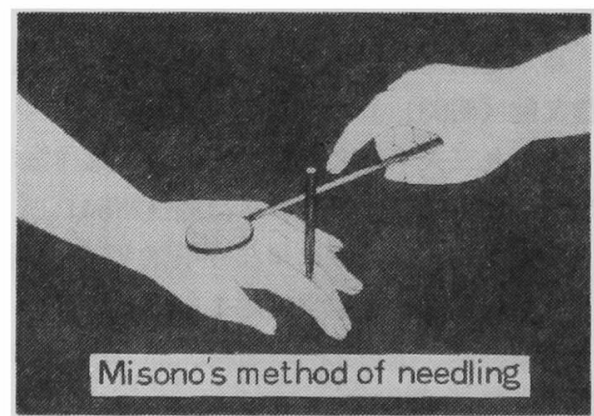

The National Medical Center Hospital

Anesthetic Dept.

Kumio YAMASHITA

Toshio YOGOSAWA

E.N.T. Dept.

Minoru TORIYAMA

from European countries.

The next few slides show some interesting historical episodes in the development of Oriental medicine in Japan. In the Momoyama era (1573-1603) Isai Misono treated a weakened peony in the emperor's garden and resuscitated it by acupuncture. The emperor was so pleased that he awarded him the honorable family name of Misono which means the palace garden. (Fig. 1)

Waichi Sugiyama, one of the well-known acupuncturists in the Tokugawa era (16031868), who because of blindness wasn't able to learn acupuncture very well, one day visited Enoshima cave shrine to pray for help to be able to do his work. He prayed earnestly with tears and then fell asleep. During his sleep he was given a dream in which the goddess Benten in the Enoshima shrine taught him to use a tube through which a needle could be passed for acupunc-

Fig. 2

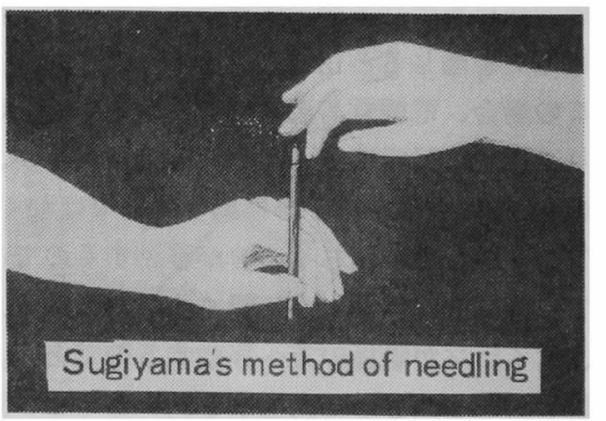


ture. So inspite of his handicap of blindness, he became an excellent acupuncturist using those tubes. (Fig.2)

Seishu Hanaoka (1760-1835) used some herbs for general anesthesia. He tried using Mafutsu-To (Mandarage and other herb plants) for a mastectomy 50 years before the first use of nitrous oxide in the U.S.A.

The tips of Maguey, it is said, were used as needles for acupuncture in your country in olden times, so that makes Mexico the first country in the American continents where acupuncture has been tried. It may be possible that acupuncture analgesia can also be done by using those needles.

Independent from Chinese acupuncture analgesia, Kobei Akabane used acupuncture analgesia in obstetrics, and it has been used for operations during delivery since 1954 in Japan. In 1969 Michio Tani and Yoshio Manaka used it for an appendectomy. Since 1950 electricity has been used in Japan for acupuncture treatment, introduced by Dr. Nakatani who was the pioneer of electric acupuncture in Japan. It is called Ryodoraku therapy.

I made a survey about the tendency of acupuncture and acupuncture analgesia in Japan using a questionnaire and the results indicated that since 1975 the use of acupuncture analgesia has declined and yet the number of hospitals where acupuncture treatment is used has increased gradually since

Fig. 3

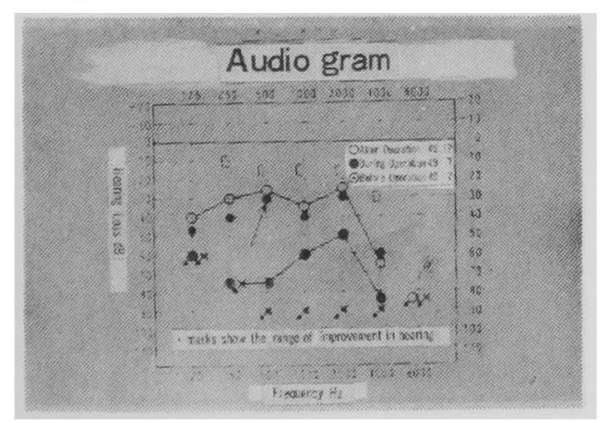

that same year. This means that even though acupuncture analgesia itself is gradually becoming less popular in Japan, acupuncture treatment is becoming more popular in the big hospitals by the stimulation of ACUPUNCTURE ANALGESIA. It is not said in Japan that acupuncture analgesia is very useful ; however, the indications of acupunciture and acupuncture analgesia are becoming clearer.

Now, what are the exact indications of acupuncture analgesia? The answers according to the questionnaire are as follows :

1) For patients who cannot have any medical anesthesia because of its severe side effects $37 / 200$

2) Anesthesia in shock condition 10

3) Anesthesia on the region above the neck

4) Obstetric anesthesia

5) Simple anesthesia which does not need to be done by a specialist 4

6) Others 10

From this we can see that in Japan acupuncture anesthesia is mainly used for head, face, dental and obstetric operations, and seldom for those of the chest and abdomen. 1)

Of course acupuncture anesthesia has many

Fig. 4

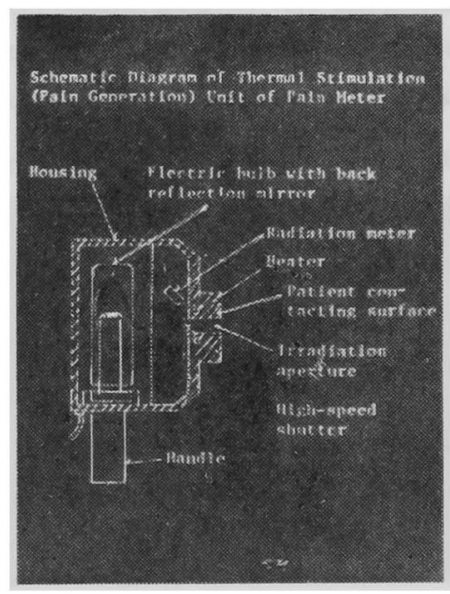


merits; say, it is safe, simple, cheap, fewer side effects after anesthesia, and patients can cooperate with the operators during surgery. However, it also has some serious demerits, one of which is that its effectiveness in uncertain. Anesthetics must be $100 \%$ effective in the operation theatre. During an operation when we try acupuncture anesthesia our anesthetists are seriously concerned about whether or not it is really effective. Some surgeons in Japan often try acupuncture anesthesia on themselves. During the operation they also have the responsibility for the anesthesia and if they find that acupuncture is not effective they themselves can add local analgesia.

Here I will show one good example of acupuncture analgesia. This 60-year old lady had plastic surgery on the tympanitic cave for her hearing difficulty.

Merits of acupuncture analgesia for this operation were :

1) When using local anesthetics the muscle facia which may be used for the new tympanum has no odema. 2) The patient can cooperate with the operator and can answer the test of hearing ability, and the operator can thus fix the artificial small ear bones and membranes in the most suitable position.

3) The needles which are used for acupuncture analgesia can be used directly for the test of facial nerve function during the operation.

Fig. 5

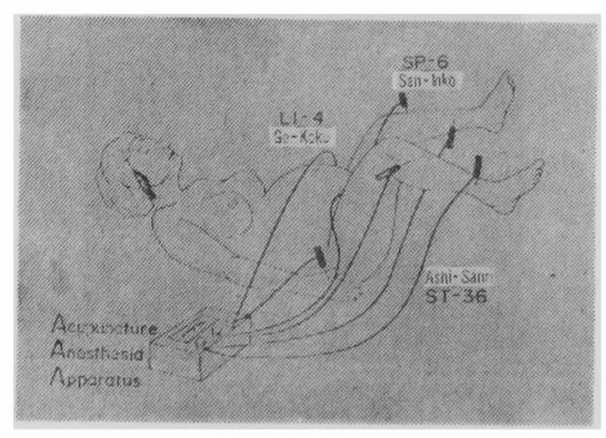

This slide shows the audiograph of that patient. The double round mark shows the pre-operative condition, the white mark, during the operation and the black mark the post-operative condition. You can see that the opertion using acupuncture analgesia was successful and that the placement of the small ear bones and membrances was very nicely done during the operation. (Fig. 3)

One of the disadvantages of acupuncture analgesia is the marked differences in anesthetic effect from person to person, so it is necessary to know before surgery what type of patients may show good results and what type insufficient results. Some anesthetists do preliminary tests several times before the operation. However some patients who showed effective results in the preliminary test did not always show good results during the actual operation. Dr. Hyodo said that the measurement of the pain threshould of the LI $4\left(\mathrm{H}_{6} 4\right)$ by the test of the algesimeter coincided with the results during the actual operation and recommended the use otf this newly devised machine for the measurement of the threshold of pain.

The principle of this algesimeter is to expose the radiant heat to the spot where one wishes to know the threshold of pain.

Fig. 6

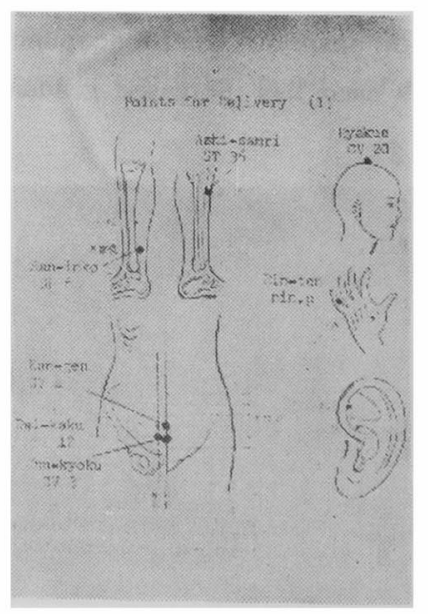


The measurement of the pain threshold is determined by the doses of radiant heat. It is said that the accuracy and consistency of this algesimeter are the most reliable in the world. 2) (Fig. 4)

Other methods to reveal the effectiveness of acupuncture analgesia are 1) the sensation of several important meridian points; for example $\mathrm{HC} 6\left(\mathrm{H}_{2} 4\right)$ or LI $4\left(\mathrm{H}_{6} 4\right)$ 2) some autonomic nerve test ; for example, perspiration or skin temperature change after needle insertion, and 3) the general condition of the patients especially from the viewpoint of Oriental medicine. This is completely my own thinking and based on little experimental data, but can we not say that the tendency of fullness presupposes good results of acupuncture analgesia? When you try acupuncture analgesia hereafter, I recommend that you check the patient's Ryodoraku Test chart before the operation and then after the operation check to see if the results are not in any way related to the fullness and emptiness of the patient's condition.

Two other important weak points of acupuncture analgesia are lack of muscle relaxation and poor analgesic effect at the traction of the viscera. There are no suitable treatment methods for these even in the People's Republic of China, I am told.

As for obstetric anesthesia, I have little experience so I will introduce two medical doctor's papers here.

Fig. $?$

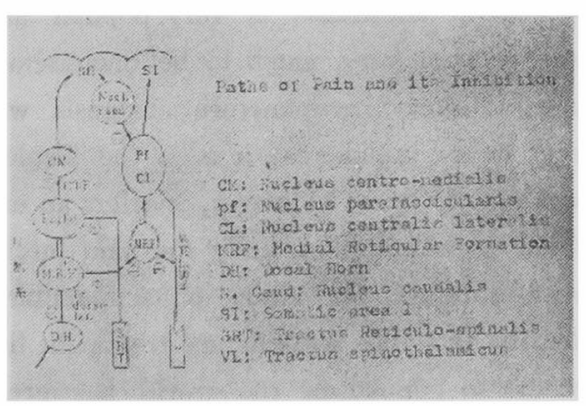

For delivery Dr. Hyodo used LI $4\left(\mathrm{H}_{6} 4\right)$, SP $6\left(F_{1} 6\right)$ and ST $36\left(F_{6} 9\right)$ when the cervix becamed dilated to $2.5-3$ fingerwidths, while in the primipara they waited until it was 3. 5-5 fingerwidths. This corresponds to the time when the anesthetic would be injected through the catheter while giving extradural anesthesia, if drug anesthesics were used. The spike form wave at at a frequency of 3-4 herz and electro-stimulation were continued until the completion of the delivery (third stage). (Fig. 5) The results indicated that among the primipara $62.5 \%$ had good or excellent effects according to the subjective scale, and $62.7 \%$ by objective assessment. Of the multipara $93.8 \%$ reported subjective relief and the objective relief was assessed at $93.7 \% .^{3}$

Dr. Kakizaki used SP $6\left(\mathrm{~F}_{1} 6\right)$, LI $4\left(\mathrm{H}_{6} 4\right)$, and ST $36\left(\mathrm{~F}_{6} 9\right)$ at the beginning of delivery, and at the second stage used CV 4 (VM 3) and CV 3 (VM 2), and then $\mathrm{KI}$ $12\left(\mathrm{~F}_{3} 13\right), \mathrm{GV} 20$ (HM 26), CV 1, etc. $\mathrm{He}$ added GB $26\left(F_{5} 20\right)$ (one of the extraordinary points) especially for labor pain. (Fig. 6) According to the point system evaluation $81.7 \%$ showed good results. ${ }^{4)}$ One of the great advantages of acupuncture analgesia for delivery is the improvement of the delivery process. Though there are drawbacks; say, restricting the activity of the patient, fear's of acupuncture by the patients, troublesome procedures for the doctors etc., the advant-

Fig. 8

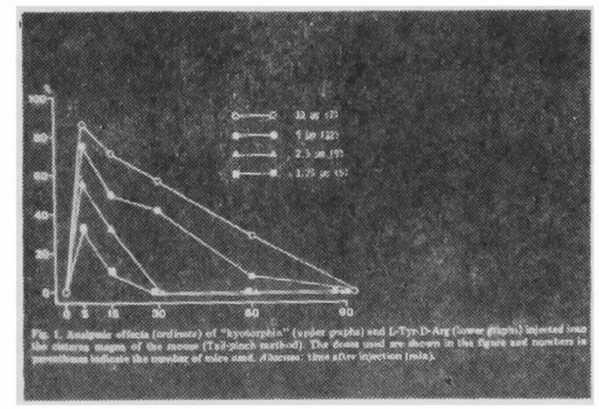


ages far outweigh them and doctors who have begun to use acupuncture analgesia for deliveries recommend it highly.

The mechanism of acupuncture analgesia is explained from the physiological side as follows : One of the paths of pain is through VL (tractus spinno-thalamicus), PF (nucleus para-fasciculous), CL (nucleus centralislateralis), and continues to S I (sensory area I). Another path is through SRT (Tractus reticulo spinalis) and the pain is transmitted partly by MRF (medial reticular formation) but mainly by Rapfe (nucleus rapfe) and CTF (central tractus fascicularis) and continues to CM (nucleus centro-medialis). According to Professor Chan in Shanghai there is a so-called inhibition system in $\mathrm{CM}$ and Raphe ; However Raphe is not directly inhibited but once their stimulation reached $\mathrm{SH}$ (sensory area $\mathbb{H}$ ) through Nucleus caudalis, $\mathrm{PF}$ and $\mathrm{CL}$ it is suppressed. The suppression mechanism works through TR.dorsolateralis and inhibits the stimulation from the dorsal horn. As shown in the upper figure, Nucleus dolsalis is seen, especially by physiologists in the People's Republic of China, as a very important area to suppress the paths of pain, ${ }^{5)}$ (Fig. 7)

Of late has come to our attention that addiction of morphine and withdrawal syndrome are improved by acupuncture and electrical stimulation. (Wen and Cheung, 1974). The Lung point and shen-men for auricular electro-acupuncture and used for the treatment of addiction of morphine. Furthermore, naloxone, and antagonist of morphine, also suppresses the effect of acupuncture analgesia caused by LI $18\left(\mathrm{H}_{6} 22\right)$ and GB $34\left(\mathrm{~F}_{5} 11\right)$ in cats. (Pomeranz) These facts show that acupuncture analgesia is minutely concerned with morphine-like substances in the brain. In 1973 it was discovered that enkephaline which is extracted from the brain suppresses the contraction of the intestines and has strong affinity to the morphine receptor. In 1976 this kind of morphine substance was extracted from the hypophysis and named endorphine.

After revealing the beta lipoprotein structure which consists of 91 amino acids and is one kind of front lobe hormone of the hypophysis it was also clear that enkephaline has 61 to 65 , alpha endorphine 61 to 76 , gamma endorphine 61 to 77 and beta endorphine, which has the strongest analgetic effect, has 61 to 91 amino acids. In Japan Dr. Takagi discovered a very simply-structured morphine-like substance called Kyotorphine which may also have some relation to the acupuncture mechanism. ${ }^{6}$ (Fig. 8)

Several of the future problems concerning acupuncture analgesia are: 1) Why does acupuncture analgesia have specific meridian points and why is less effectiveness expected if there is no needle sensation? 2) Is it possible to have a kind of acupuncture analgesia which can be used together with general anesthesia? and 3) How can we get more muscle relaxation and improve the poor analgesic effect at the traction of the viscera?

Conclusion: "To do or not to do, that is the question!" These words, spoken by a doctor at the last World Congress held here in Mexico, are very impressive as a critique about acupuncture. Perhaps in the U.S.A., European countries and Japan where general anesthesia is very popular and patients want very much to be unconscious during surgery, acupuncture analgesia will never be as popular as it is in the Peple's Republic of China. However, it offers an excellent opportunity to study the pain mechanism through the study of acupuncture. Also the fact that acupuncture treatment has become so popular in the world has great 
meaning, I think.

1）山下九三夫：わが国のハリ麻酔・鋮治療の 現況について、麻醉、28(4), 421 429(1979)

2) Hyodo M. and K. Masayama : The Advanced of Acupuncture Anesthesia, Presented at the $\mathbb{I}$ nd East-African Congress of Anesthesiology, Oct. 1974

3) Hyodo M. and O.Gega : Use of Acupuncture Anesthesia for Normal Delivery, Am. J. of chin. Med., 5(1)63 69(1977)
4）懢崎要・木村制哉：ハリによる和痛分婏、 産科・新生児、年間追補、'77一D, 375 411 (1977)

5）高木健太郎：ハリ麻配とそのメカニズム、 産科・新生児、年間追補、' $77-\mathrm{D}, 307 \sim 329$ (1977)

6) Takagi, H. : Morphine like Analgesia by a New Dipeplide, L-Tyrosyl-Arginine (Kyotorphin) and its Analogue, Europ. J. of pharm. 55, 109 111(1979) 